\title{
Influence of Temperature and Freezing Time on Broiler Chicken Meat Colour
}

\author{
Marius Mihai CIOBANU*, Roxana LAZĂR, Paul Corneliu BOIŞTEANU
}

Department of Fundamental Sciences in Animal Husbandry, "Ion Ionescu de la Brad" University of Applied Life Sciences and Environment, 8 Mihail Sadoveanu, 700489, Iaşi, Romania

*Corresponding authors, e-mail: mar.ciobanu@yahoo.com

Bulletin UASVM Animal Science and Biotechnologies 73(1)/ 2016

Print ISSN 1843-5262; Electronic ISSN 1843-536X

DOI:10.15835/buasvmcn-asb: 11678

\begin{abstract}
Due to the fact that meat colour represents an important aspect for sensorial evaluation of any food product, research in the field of poultry meat processing regarding efficient methods for hoarding/storage on long term of industrially slaughtered poultry carcasses approaches a continuous finding/optimization of certain solutions for avoiding negative consequences due to oxidation, which could include colour loss and/or its modification.

The current study aimed to evaluate the effects of three storage regimes differing by temperature and time $\left(\mathrm{L}_{1}=-14^{\circ} \mathrm{C}, 30\right.$ days; $\mathrm{L}_{2}=-16^{\circ} \mathrm{C}, 60$ days; $\mathrm{L}_{3}=-18^{\circ} \mathrm{C}, 90$ days) on three anatomical cut regions (breast, upper thigh and lower thigh), to characterize the colour of broiler chicken meat. Objective description of colour for frozen and defrosted chicken meat was realised through the CIEL*a*b* Cartesian coordinate system.

Overall, the preservation method determines a higher luminosity at samples gathered from $\mathrm{L}_{3}$ batch chicken carcasses for breast and upper thigh musculature, and $\mathrm{L}_{2}$ for lower thigh musculature in comparison with the counterparts from the other experimental batches.
\end{abstract}

Keywords: chicken meat, freezing, colorimetric parameters, luminosity.

\section{INTRODUCTION}

Freezing represents a preservation method of poultry meat at temperatures below $-10{ }^{\circ} \mathrm{C}$, a process which influences meat quality by two related processes: temperature decrease and change of water state from liquid to solid. Both processes tend to reduce the levels of physical and chemical modifications, being able to increase shelf lifetime of meat (Barbut, 2002).

This process concentrates a series of chemical solutions, including salts and small organic molecules (Blond and Le Meste, 2004). The appearance of ice crystals affects other structures, such as cell membranes and various polymer aggregates (micelles). Separation of water as pure ice freeze-concentrates the unfrozen solution. These modifications affect important descriptive parameters of meat quality, such as colour (Karel and Lund, 2003).
Visual appearance of meat and meat products is the first factor influencing consumers' purchasing decision. As a result of the strong psychological impact, meat colour is a sensitive point from producers' perspective, and in order to prevent the occurrence of unwanted chromatic modifications, a series of studies have been conducted to clarify the origin of meat colour as well as understand the factors which could influence its change during processing, storage or preparation (Guidi and Castigliego, 2010).

Recent research evaluated the problems caused by the colour of poultry meat subjected to freezing and thermal treatment; discoloration of raw or boiled muscular tissue is a consequence of breaks and migration of sanguine cells, due to a low chilling rate (Lyon and Lyon, 2002). In addition, storage through freezing leads to darkening of poultry meat and acquisition in time 
of a more reddish or yellowish colour (Heath and Owens, 1992), leading to a decrease of shelf lifetime simultaneously with development of an unpleasant and darker colour(Allen et al., 1997).

\section{MATERIALS AND METHODS}

The study aimed to evaluate three storage regimes differing by temperature and time $\left(\mathrm{L}_{1}=\right.$ $-14{ }^{\circ} \mathrm{C}, 30$ days; $\mathrm{L}_{2}=-16{ }^{\circ} \mathrm{C}, 60$ days; $\mathrm{L}_{3}=-18{ }^{\circ} \mathrm{C}$, 90 days), on three anatomical cut regions (breast, upper thigh and lower thigh), to characterize the colour of broiler chicken meat. Meat colour was expressed by tristimulus spectral coordinates $\mathbf{L}^{*}, \mathbf{a}^{*}, \mathbf{b}^{*}$ in CIEL*a*b* colorimetric space, being corrected by DIN99 equation, measured through specular component included (SCI); entire spectrophotometer operating principle applying specifications given in "CIE Colorimetry Second Edition, Publication 15.2 (1986)" (CIE 1976).

In the current study, colour determination was realised on meat samples with a thickness of 15 $50 \mathrm{~mm}$, those ones being perpendicular sections on the longitudinal axis of anatomical cut regions (breast, upper thigh and lower thigh) gathered from broiler chickens. Samples were gathered 24 hours after slaughtering, and afterwards the meat samples were subjected to three storage regimes differing by temperature and time $\left(\mathrm{L}_{1}=-14{ }^{\circ} \mathrm{C}, 30\right.$ days; $\mathrm{L}_{2}=-16^{\circ} \mathrm{C}, 60$ days; $\mathrm{L}_{3}=-18^{\circ} \mathrm{C}, 90$ days), until performing the colorimetric measurements. Prior to determinations, meat samples were maintained for 24 hours at $2-4^{\circ} \mathrm{C}$ for slow defrosting.

As working procedure, measurement itself was carried out in three different areas for each meat sample using Minolta CM-2600d portable spectrophotometer. Chromometer calibration was performed before each series of measurements with Minolta CM-A32 calibration device; the calibration principle was based on a "black standard" and a "white standard". The obtained values were transformed and processed using SpectraMagic v.3.30 software.

\section{RESULTS AND DISCUSSIONS}

Since the colour of meat is an important aspect in evaluating any food product, poultry research regarding effective methods of storage/ long term storage of industrially slaughtered chicken carcasses aims to identify/continuously optimise some solutions in order to avoid the negative consequences caused by oxidation, which may include loss of colour and / or its modification (Fletcher, 2002).

The statistical indicators calculated for all three descriptive colorimetric parameters for the chicken meat stored as frozen recorded values for the standard error of the mean that were scored in the following limits: $L^{*}(0.411-1.184), a^{*}(0.079-$ $0.584)$ and $b^{*}(0.225-0.992)$ (tab. 1).

The calculation of the variation coefficient for the values describing the brightness and the coordinate of complementary colors yellow - green $\left(b^{*}\right)$ of all three muscle categories of the slaughtered chickens from the experimental groups showed great or medium $(\mathrm{L}=\mathrm{V} \% 2.688$ - 10.961] homogeneity; $b^{*}=\mathrm{V} \% 6.436$ - 22.102]), while numerical variations achieved for the coordinate of the complementary colors red and green $\left(\mathrm{a}^{*}\right)$ described heterogeneity for the thawed meat samples (V\% 21.377 - 106.589]), (table 1).

The brightness of the studied cut anatomical regions ranged within a lower limit of $47.27 \pm 1.184$ units for lower thigh coming from the chickens of $\mathrm{L}_{3}$ group, and upper limit of $53.35 \pm 1.142$ units calculated for the upper thigh collected from the same $L_{3}$ experimetal group. The preservation method resulted in obtaining anatomical cut portions whose muscle tissue was characterized by higher brightness for the samples collected from the chicken carcasses of $\mathrm{L}_{3}$ group for the chest and upper thigh muscles, and of $L_{2}$ for the lower thigh muscle when comparing to the counterparts from the other experimental groups.

As concerns the muscle region, it has been noted that breast musculature has, on average, the most accentuated luminosity (50.42 units), followed in a descendant order by upper thigh (48.40 units) and the lower thigh (47.91 units) for $\mathrm{L}_{1}$ chicken carcasses. For muscular samples gathered from $\mathrm{L}_{2}$ chicken carcasses, the upper thigh is characterized, on average, by the lowest luminosity (49.11 units), followed by the means obtained for lower thigh (49.36 units) and pectoral musculature (50 units). Musculature gathered from carcasses of $\mathrm{L}_{3}$ experimental batch show a maximal luminosity for upper thigh musculature (53.35 units), followed by breast luminosity (52.35 units) and that of lower thigh (47.27 units).

For the coordinates of complementary colours red - green $\left(a^{*}\right)$, the lowest level of calculated means was recorded for breast gathered from $\mathrm{L}_{1}$ chicken carcasses (-1.21 units) and the maximal 
Tab. 1.Colour characterization of $\mathrm{L}_{1}, \mathrm{~L}_{2}, \mathrm{~L}_{3}$ poultry meat subjected to freezing, after defrosting for $24 \mathrm{~h}$

\begin{tabular}{|c|c|c|c|c|c|}
\hline \multirow{3}{*}{ Specification } & \multirow{3}{*}{ Exp. batch } & \multicolumn{4}{|c|}{ HIBRID “ROSS - 308” ( $\mathrm{n}=30$ /experimental batch) } \\
\hline & & V\% & \multicolumn{2}{|c|}{$\begin{array}{l}\text { Interpretation of differences } \\
\text { T-Test(2-tailed) }\end{array}$} & \multirow[b]{2}{*}{ L1-L2 } \\
\hline & & L1 & $50.42 \pm 0.87$ & 5.461 & \\
\hline \multirow{8}{*}{$\begin{array}{l}\text { 氙 } \\
\text { 至 }\end{array}$} & $L^{*}$ & L2 & $50.00 \pm 0.69$ & 4.380 & L1-L3 \\
\hline & & L3 & $52.35 \pm 0.51$ & 3.088 & L2-L3 \\
\hline & & L1 & $-1.21 \pm 0.131$ & 34.171 & L1-L2 \\
\hline & $a^{*}$ & $\mathrm{~L} 2$ & $-0.85 \pm 0.13 \mathrm{c}$ & 51.622 & L1-L3 \\
\hline & & L3 & $-1.13 \pm 0.07 c$ & 22.188 & L2-L3 \\
\hline & & L1 & $10.67 \pm 0.25($ & 7.416 & L1-L2 \\
\hline & $\mathrm{b}^{*}$ & L2 & $11.03 \pm 0.22$ ! & 6.436 & L1-L3 \\
\hline & & L3 & $10.55 \pm 0.37 i$ & 11.160 & L2-L3 \\
\hline \multirow{9}{*}{ 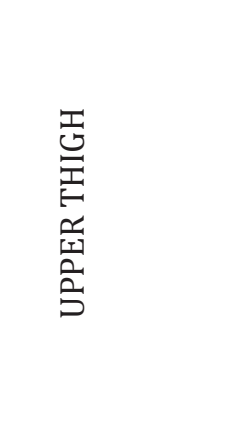 } & & L1 & $48.40 \pm 0.41$ & 2.688 & L1-L2 \\
\hline & $L^{*}$ & $\mathrm{~L} 2$ & $49.11 \pm 1.70$ ؛ & 10.961 & L1-L3 \\
\hline & & L3 & $53.35 \pm 1.14 i$ & 6.771 & L2-L3 \\
\hline & & L1 & $3.99 \pm 0.442$ & 35.031 & L1-L2 \\
\hline & $a^{*}$ & L2 & $3.31 \pm 0.284$ & 27.194 & L1-L3 \\
\hline & & L3 & $2.69 \pm 0.584$ & 68.737 & L2-L3 \\
\hline & & L1 & $11.51 \pm 0.56$ & 15.465 & L1-L2 \\
\hline & $\mathrm{b}^{*}$ & $\mathrm{~L} 2$ & $14.20 \pm 0.99$ & 22.102 & L1-L3 \\
\hline & & L3 & $16.68 \pm 0.74$ & 14.050 & L2-L3 \\
\hline \multirow{9}{*}{ 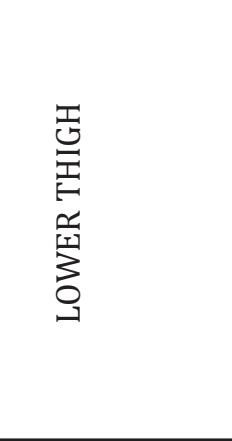 } & & L1 & $47.91 \pm 0.73 i$ & 4.832 & L1-L2 \\
\hline & $L^{*}$ & L2 & $49.36 \pm 1.45 t$ & 9.325 & L1-L3 \\
\hline & & L3 & $47.27 \pm 1.18$ & 7.920 & L2-L3 \\
\hline & & L1 & $4.20 \pm 0.501$ & 37.716 & L1-L2 \\
\hline & $a^{*}$ & L2 & $1.45 \pm 0.487$ & 106.589 & L1-L3 \\
\hline & & L3 & $4.89 \pm 0.331$ & 21.377 & L2-L3 \\
\hline & & L1 & $14.06 \pm 0.53($ & 11.927 & L1-L2 \\
\hline & $\mathrm{b}^{*}$ & L2 & $14.85 \pm 0.66$ & 14.095 & L1-L3 \\
\hline & & L3 & $11.88 \pm 0.80 t$ & 21.451 & L2-L3 \\
\hline
\end{tabular}

$\mathbf{L}^{*}=$ brightness; $\mathbf{a}^{*}=$ complementary colours coordinate red - green; $\mathbf{b}^{*}=$ complementary colours coordinate yellow - blue. T-test (two-

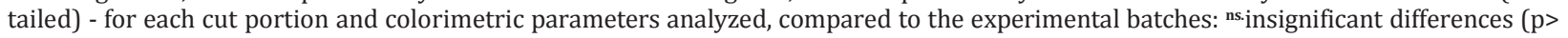
$0.05)$; *Significant differences $(\mathrm{p}<0.05) ;{ }^{* *}$ distinct significant differences $(\mathrm{p}<0.01)$; ${ }^{* * *}$ Very significant differences $(\mathrm{p}<0.001)$.

one (4.89 units) was recorded for the lower thigh of $\mathrm{L}_{3}$ chicken carcasses.

The mean calculated for the coordinates of complementary colours yellow - blue (b*) varied between 10.67 units, for pectoral musculature of $\mathrm{L}_{1}$ chicken carcasses and 16.68 units, for pectoral musculature of $\mathrm{L}_{2}$ chicken carcasses.

\section{CONCLUSION}

By comparing the effect of storage methods (freezing) on meat quality of poultry from experimental batches, it has been found that the colour of meat subjected to freezing became darker and achieve, in time, a more reddish colour in the experimental batch L3 for all studied anatomical regions.

The obtained luminosity parameter $\left(\mathrm{L}^{*}\right)$ for the analysed samples highlighted that, across the batches, the highest decreasing of luminosity occurred at pectoral musculature in comparison with the other studied anatomical regions.

\section{REFERENCES}

1. Allen, CD, Russell SM, Fletcher DL, (1997). The relationship of broiler breast meat color and $\mathrm{pH}$ to shelllife and odor development, Poulty Science, 76:10421046. 
2. Barbut S, (2002). Poultry Processing Systems, Boca Raton FL: CRC Pres.

3. Blond G, Le Meste M, (2004). Principles of frozen storage, In: Handbook of Frozen Foods: Principles of Frozen Storage, Marcel Dekker Press, New York, ch. 3.

4. Fletcher JM, (2002). Freezing, In: The Nutrition Handbook for Food Processors, Woodhead Publishing, ch. 15.

5. Guidi A, Castigliego L, (2010). Poultry meat color, In: Handbook of Poultry Science and Technology, Secondary Processing, vol. (2):359-388.
6. Heath JL, Owens SL, (1992). Effect of heating variables and storage on color of chicken cooked and stored in polyester pouches, Poultry Science, vol. (71):1773-1780.

7. Karel M, Lund D B, (2003). Freezing, In: Physical Principles of Food Preservation, Marcel Dekker Publisher, New York, ch. 8.

8. Lyon BG, Lyon CE, (2002). Colour of uncooked and cooked broiler leg quarters associated with chilling temperature and holding time, Poultry Science, vol. (81):1916-1920. 